$11,09,04$

\title{
Особенности структурных фазовых переходов в ионно-молекулярных кристаллах перхлоратов
}

\author{
(C) А.Р. Алиев, М.М. Гафууров, И.Р. Ахмедов, М.Г. Какагасанов, З.А. Алиев \\ Институт фризики им. Х.И. Амирханова ДагНЦ РАН, \\ Махачкала, Россия \\ E-mail: amilaliev@rambler.ru
}

\begin{abstract}
Методами спектроскопии комбинационного рассеяния (КР) исследованы процессы молекулярной релаксации в перхлоратах калия $\left(\mathrm{KClO}_{4}\right)$ и цезия $\left(\mathrm{CsClO}_{4}\right)$. Установлено, что в кристаллических перхлоратах $\mathrm{KClO}_{4}$ и $\mathrm{CsClO}_{4}$ структурный фазовый переход первого рода носит растянутый характер. Обнаружено существование предпереходной области в исследованных перхлоратах $\mathrm{KClO}_{4}$ и $\mathrm{CsClO}_{4}$. Показано, что в предпереходной области ширины колебательных полос мало изменяются, резко возрастая в точке фазового перехода.
\end{abstract}

DOI: $10.21883 /$ FTT.2018.06.45999.29M

\section{1. Введение}

Исследованиям структурных фазовых переходов в кристаллах в последние годы уделяется большое внимание [1-9]. Многие их них являются переходами первого рода. Известно, что в области фазового перехода первого рода „кристалл-расплав“ имеют место явления предплавления $[10,11]$. Предпереходные явления наблюдаются в жидких кристаллах [12-15]. Исследованы предпереходные явления в металлических сплавах [16-19].

Можно предположить, что подобные предпереходные явления могут наблюдаться и при некоторых структурных фазовых переходах первого рода в кристаллах. Наряду с дифракционными методами эти явления могут с успехом изучаться и спектроскопическими методами, чувствительными к локальным взаимодействиям и нарушениям в кристаллической решетке.

В работах [20-23] исследовались структурные фазовые переходы первого рода в кристаллах $\mathrm{KPb}_{2} \mathrm{Br}_{5}$, $\left(\mathrm{NH}_{4}\right)_{2} \mathrm{WO}_{2} \mathrm{~F}_{4}, \mathrm{KPb}_{2} \mathrm{Cl}_{5},\left(\mathrm{NH}_{4}\right)_{2} \mathrm{NbOF}_{5}$. При повышении температуры разность показателей преломления сначала изменялась линейно и незначительно, а за $30 \div 130 \mathrm{~K}$ до температуры фазового перехода наблюдается аномальное поведение двупреломления. Это особая температурная точка на температурных зависимостях. В этих кристаллах в широком интервале температур выше фазового перехода наблюдались сильные предпереходные явления, растянутые по температуре на $\approx 30 \div 70 \mathrm{~K}$.

Теоретические представления о предпереходных состояниях развиты в работах [24-27].

В качестве метода исследования структурных фазовых переходов в кристаллах удобен метод колебательной спектроскопии, в том числе и метод комбинационного рассеяния (КР) света $[28,29]$. В отличие от других методов в колебательной спектроскопии измеряются величины, характеризующие непосредственно отдельные молекулы или ионы изучаемой системы. Этими параметрами являются положение максимума (частота $v$ ) и ширина $\delta$ спектральной полосы. Малейшие изменения в микроскопической структуре и строении изучаемой системы, а также в динамике молекул и ионов отражаются на спектральных параметрах $(v, \delta)$ этой системы.

Поэтому исследование предпереходных явлений при структурных фазовых переходах первого рода в кристаллах методом КР может способствовать установлению характера изменения механизма ионной динамики при структурном фазовом превращении. Тем более что при исследовании фазовых переходов типа „порядокбеспорядок“ в нитратах щелочных металлов обнаружены предпереходные явления, изучение которых важно для понимания динамики процессов разупорядочения и ориентационного плавления в области растянутых фазовых переходов [30,31]. С точки зрения структуры рассматриваемых фаз, некоторые превращения в твердом состоянии оказываются чрезвычайно важными для исследования и интерпретации процессов плавления.

В наших предыдущих работах мы исследовали область предплавления в кристаллах с многоатомными ионами методом колебательной спектроскопии [32]. При этом было установлено, что область предплавления наиболее четко проявляется в тех кристаллах, где выше симметрия молекулярного иона. В соответствии с этим, в настоящей работе в качестве объекта исследования нами были выбраны перхлораты калия $\left(\mathrm{KClO}_{4}\right)$ и цезия $\left(\mathrm{CsClO}_{4}\right)$. Указанные соли содержат тетраэдрический молекулярный перхлорат-ион $\mathrm{ClO}_{4}^{-}$(симметрия $T_{d}$ ), имеющий определенный набор нормальных колебаний с хорошо изученным спектром и активных в КР во всех фазовых состояниях. Это позволяет нам надеяться на то, что исследование колебательных спектров вблизи структурного превращения позволит обнаружить предпереходную область. Исследование фазового перехода в перхлоратах важно для понимания механизма и молекулярной природы структурных перестроек в твердых телах [33]. В литературе мало данных, посвященных исследованиям именно этого класса ионных соединений [34-39]. Поэтому исследование реориентационной подвижности и процессов разупорядочения анионов 
в области полиморфных превращений в перхлоратах щелочных металлов методом КР является актуальной задачей.

Таким образом, в настоящей работе мы исследуем спектры КР перхлоратов калия и цезия в окрестности структурного фазового перехода первого рода с целью выявить предпереходную область и изучить особенности процессов колебательной и ориентационной релаксации в этой области.

\section{2. Объекты исследования}

При атмосферном давлении $\mathrm{KClO}_{4}$ имеет две полиморфные модификации [40]. Низкотемпературная фаза II имеет орторомбическую структуру типа барита, параметры решетки $a=9.840 \cdot 10^{-10} \mathrm{~m}$, $b=6.012 \cdot 10^{-10} \mathrm{~m}, c=7.806 \cdot 10^{-10} \mathrm{~m}$, пространственная группа $P_{n m a}$. При температуре $T_{0}=300^{\circ} \mathrm{C}$ происходит переход II-I, сопровождающийся $\Delta H=15.1 \mathrm{~J} \cdot \mathrm{mol}$. Высокотемпературная фаза I имеет кубическую структуру, $a=7.515 \cdot 10^{-10} \mathrm{~m}$, пространственная группа $T^{4}$. При $T=582^{\circ} \mathrm{C}$ кристалл плавится [40].

При атмосферном давлении $\mathrm{CsClO}_{4}$ имеет несколько кристаллических модификаций. Низкотемпературная модификация III имеет орторомбическую структуру, параметры решетки $a=7.813 \cdot 10^{-10} \mathrm{~m}, b=9.848 \cdot 10^{-10} \mathrm{~m}$, $c=6.029 \cdot 10^{-10} \mathrm{~m}$, пространственная группа $P_{n m a}-D_{2 h}^{16}$. Фазовый переход III-II происходит при $T_{0}=209^{\circ} \mathrm{C}$ c $\Delta H=7.5 \mathrm{~kJ} \cdot \mathrm{mol}$. Высокотемпературная фаза II имеет кубическую структуру, $a=7.99 \cdot 10^{-10} \mathrm{~m}$, пространственная группа $F_{m 3 m}-\mathrm{O}_{h}^{5}[40]$.

Молекулярный анион $\mathrm{ClO}_{4}^{-}$характеризуется следующими колебаниями: $v_{1}(A)$ - валентное полносимметричное колебание $\left(935 \mathrm{~cm}^{-1}\right), \nu_{2}(E)$ - дважды вырожденное колебание $\left(460 \mathrm{~cm}^{-1}\right), v_{3}\left(F_{2}\right)$ - трижды вырожденное колебание $\left(1100 \mathrm{~cm}^{-1}\right), v_{4}\left(F_{2}\right)$ - трижды вырожденное колебание $\left(630 \mathrm{~cm}^{-1}\right)[33,34]$.

При комнатной температуре свободный перхлоратион $\mathrm{ClO}_{4}^{-}$имеет симметрию тетраэдра $\left(T_{d}\right)$ и все девять его колебаний должны быть активны в спектре КР. Здесь наблюдаются четыре линии рассеяния: линия полносимметричного колебания $v_{1}(A)$, линия дважды вырожденного колебания $v_{2}(E)$ и линии трижды вырожденных колебаний $v_{3}\left(F_{2}\right)$ и $v_{4}\left(F_{2}\right)$. В то же самое время в соответствии с правилами отбора в ИК-спектре для $\mathrm{ClO}_{4}^{-}$должны наблюдаться полосы лишь трижды вырожденных колебаний $v_{3}$ и $v_{4}$. Дело обстоит именно таким образом, если речь идет о водных растворах перхлоратов в спектрах КР, в которых наблюдаются линии с частотами $935-v_{1}(A), 460-v_{2}(E), 1100-$ $v_{3}\left(F_{2}\right)$ и $630 \mathrm{~cm}^{-1}-v_{4}\left(F_{2}\right)[33,34]$.

Иную картину мы имеем в случае твердых кристаллических перхлоратов, спектры которых значительно усложняются. В спектрах КР в области колебаний $v_{1}, v_{2}, v_{3}$ наблюдается увеличение числа линий, а в
ИК-спектре наряду с „расщеплением“ полос колебаний $v_{3}$ и $v_{4}$ - слабая полоса полносимметричного колебания $v_{1}$. Определяющей причиной этого явления, по мнению авторов [39], следует считать то обстоятельство, что происходит нарушение (понижение) симметрии перхлорат-иона вследствие его искажения в кристаллической решетке. „Тетраэдрический“ ион $\mathrm{ClO}_{4}^{-}$ как в случае $\mathrm{KClO}_{4}, \mathrm{CsClO}_{4}$, так и в случае $\mathrm{NaClO}_{4}$ искажен и имеет симметрию $C_{2 v}$ с несколько различающимися по длине связями $\mathrm{Cl}-\mathrm{O}$. Правда, даже в случае $\mathrm{NaClO}_{4}$ это различие невелико: $\mathrm{Cl}-\mathrm{O}_{1}=1.432 \cdot 10^{-10} \mathrm{~m}$ и $\mathrm{Cl}-\mathrm{O}_{2}=1.437 \cdot 10^{-10} \mathrm{~m}$. Поэтому переориентации искаженного перхлорат-иона влияют на ширину изотропного контура, соответствующего моде $v_{1}(A)$. Полносимметричное (в изолированном ионе $\mathrm{ClO}_{4}^{-}$) колебание $v_{1}(A)$ обладает малой величиной дипольного момента перехода и соответственно узкой зонной в кристалле. Благодаря этому оно является хорошим „зондом“ симметрии кристаллического поля и ее нарушений [31].

Перхлораты щелочных металлов, за исключением $\mathrm{LiClO}_{4}$, являются диморфными, т.е. могут находиться в низкотемпературной или высокотемпературной кристаллической модификации. Перхлораты натрия, калия и цезия претерпевают фазовые переходы в области температур $T_{0} \approx 200-310^{\circ} \mathrm{C}$. Эти кристаллы имеют кубическую симметрию $T_{d}^{2}(F \overline{43} m)$ в высокотемпературной $\left(T>T_{0}\right)$ и ромбическую $D_{2 h}^{16}\left(V_{n}^{16}\right)$ в низкотемпературной $\left(T<T_{0}\right)$ фазах [33,34].

В низкотемпературной ромбической фазе элементарная ячейка кристалла перхлората содержит 4 формульных единицы и должна иметь 69 оптических колебаний с волновым вектором $q=0$. Однако, поскольку внутрикристаллические поля, в которых находятся подобные группы $\left(\mathrm{ClO}_{4}^{-}\right.$и искаженные октаэдры $\left.\mathrm{MClO}_{4}\right)$ элементарной ячейки, отличаются на малые величины, ряд полос, обусловленных внутренними и внешними колебаниями кристаллической решетки, перекрываются так, что общее число наблюдаемых спектральных полос меньше 69. В ромбической фазе полностью снимается вырождение нормальных колебаний с $q=0$, так как их координаты преобразуются по одномерным представлениям группы $D_{2 h}[33]$.

Спектры перхлоратов в высокотемпературной кубической фазе существенно проще спектров этих же кристаллов при $T<T_{0}$, что обусловлено высокой симметрией кристаллической решетки. Элементарная ячейка перхлоратов в высокотемпературной кубической фазе содержит одну формульную единицу. Групповой анализ показывает, что в кубической фазе нормальные колебания (с волновым вектором $q=0$ ) кристаллов распределены по типам симметрии следующим образом:

$$
\Gamma=A_{1}+E+F_{1}+4 F_{2} .
$$

При вычислении числа нормальных колебаний различного типа (1) значения основных векторов кристаллической решетки $\mathrm{MClO}_{4}\left(T_{d}^{2}\right)$ взяты из таблиц пространственных групп [41]. В разложении (1) колебания типа 
$2 F_{2}, E, A_{1}$ определяются группой $\mathrm{ClO}_{4}^{-}$и являются внутренними колебаниями кристаллической решетки [42]. К внешним длинноволновым оптическим колебаниям относятся вращательные колебания $F_{1}$ группы $\mathrm{ClO}_{4}^{-}$, трансляционное колебание $F_{2}$. Одно из колебаний типа $F_{2}$ является акустическим $v=0(q=0)$.

\section{3. Эксперимент}

Исследования проводили методом спектроскопии КР на спектрометре ДФС-24. Спектры КР, возбуждаемые аргоновым лазером $\left(\lambda_{0}=488 \mathrm{~nm}\right)$, регистрировались при щелях монохроматора $100-150 \mathrm{mcm}$. Температуру образцов поддерживали с точностью $\pm 1^{\circ} \mathrm{C}$ при помощи высокоточного регулятора температуры ВРТ-2 и измеряли отградуированной термопарой хромель-алюмель. Положение максимума спектральной полосы и ее ширина измерялись с точностью $\pm 0.5 \mathrm{~cm}^{-1}$ и $\pm 0.2 \mathrm{~cm}^{-1}$ соответственно [43].

Повышение температуры кристаллов от комнатной до температуры фазового перехода приводит к изменению параметров практически всех наблюдаемых в спектре полос. Общим свойством для всех спектров является смещение максимумов в низкочастотную область, уширение спектральных линий и упрощение их формы по мере повышения температуры и при переходе из низкотемпературной в высокотемпературную фазу. Вместе с тем для каждого кристалла наблюдаются свои особенности изменения спектров при температурных изменениях и фазовых превращениях. Поэтому ниже приведем обсуждение применительно к каждой соли в отдельности.

\section{4. Результаты по перхлорату калия}

Спектры КР перхлората калия снимали в области полносимметричного колебания $v_{1}(A)$, а также в области $v_{2}(E)$ - дважды вырожденного колебания и $v_{4}\left(F_{2}\right)$ - трижды вырожденного колебания. Динамика реориентационного движения молекул (или молекулярных групп) в кристалле, определяющая характер фазового перехода, спектроскопически проявляется в изменении вида колебательных спектральных полос. Однако, поскольку общая теория реориентационного движения молекул в кристаллах отсутствует, анализ температурных изменений контура линии в колебательных спектрах кристаллов производится либо как в жидкостях и газах на основе теории вращательной диффузии с непрерывным распределением по углам, либо на основе модели броуновской переориентации в периодическом поле, результаты которой мало отличаются от результатов для жидкости [44]. Оценку параметров переориентации по линиям КР проводили на основании температурных зависимостей их ширин.

Анализ температурно-фазовых зависимостей колебательных спектров солей, содержащих молекулярные ио- ны, показал, что причины, обусловливающие изменения частот колебаний и ширину спектрального контура, могут быть разными. В общем случае ширина спектральной полосы $\delta$ есть сумма следующих вкладов [45]:

$$
\delta=\delta_{v d}+\delta_{\text {res }}+\delta_{\text {rep }}+\delta_{i d}+\delta_{d d}+\delta_{R},
$$

где $\delta_{v d}$ - вклад в ширину полосы, обусловленный колебательной дефазировкой; $\delta_{r e s}-$ уширение за счет резонансной передачи колебательных квантов между идентичными молекулами; $\delta_{r e p}-$ отталкивательное уширение; $\delta_{i d}-$ ион-дипольное уширение; $\delta_{d d}-$ дипольдипольное уширение; $\delta_{R}$ - вклад, обусловленный переориентацией. Вероятность резонансной передачи колебательных квантов в ионных системах мала, поскольку ближайшими соседями анионов являются катионы. Поэтому мы считаем, что $\delta_{r e s} \approx 0$. Остальные причины уширения, кроме $\delta_{v d}$, зависят от времени переориентации и поэтому можно записать

$$
\delta(T)=\delta_{v d}+\text { const }_{1} \cdot\left(\pi c \tau_{R}\right)^{-1}, \quad c=3 \cdot 10^{10} \mathrm{~cm} / \mathrm{s} .
$$

Кроме того, $\tau_{R}$ гораздо в большей степени, чем $\delta_{v d}$, зависит от температуры. Поэтому можно считать, что температурная зависимость $\delta$ обусловлена в основном переориентацией.

Время переориентации может быть найдено из условия

$$
\tau_{R}=\tau_{0} \exp (U / R T), \quad R=8.31 \mathrm{~J} /(\mathrm{mol} \cdot \mathrm{K}),
$$

описывающего переориентацию как активационный процесс. Считается, что частица расположена в ориентационной потенциальной яме глубиной $U$ и совершает там вращательные качания с полупериодом $\tau_{0}$, называемые либрационными колебаниями. Накопив достаточную энергию, она преодолевает потенциальный барьер, меняя свою ориентацию скачком. Время между двумя такими последовательными скачками составляет $\tau_{R}$. Тогда

$$
\delta(T)=\delta_{0}+A \exp (-U / R T),
$$

где $\quad A=1 / \pi c \tau_{0}=2 v_{L} / \pi=$ const $_{2} ; \quad \delta_{0}=\delta_{v d}=$ const $_{3}$, $\delta_{L}$ - частота либрационных колебаний. Таким образом, основной вклад в ширину спектральной полосы дают процессы колебательной дефазировки и ориентационной релаксации.

Температурные зависимости положений максимумов и ширин спектральных контуров, соответствующих колебаниям $v_{1}(A), v_{2}(E)$ и $v_{4}\left(F_{2}\right)$ аниона $\mathrm{ClO}_{4}^{-}$в кристаллическом перхлорате калия, исследовались в интервале $20-410^{\circ} \mathrm{C}$.

Для колебания $v_{1}(A)$ (рис. 1) было обнаружено, что в интервале температур $20-200^{\circ} \mathrm{C}$ температурная зависимость $\Delta_{R}$ имеет экспоненциальный характер. При температуре $T \approx 200^{\circ} \mathrm{C}$ наблюдается перегиб и рост ширины с температурой замедляется. Частота на этом интервале линейно уменьшается. В области фазового перехода наблюдается излом температурных зависимостей частоты и ширины. 

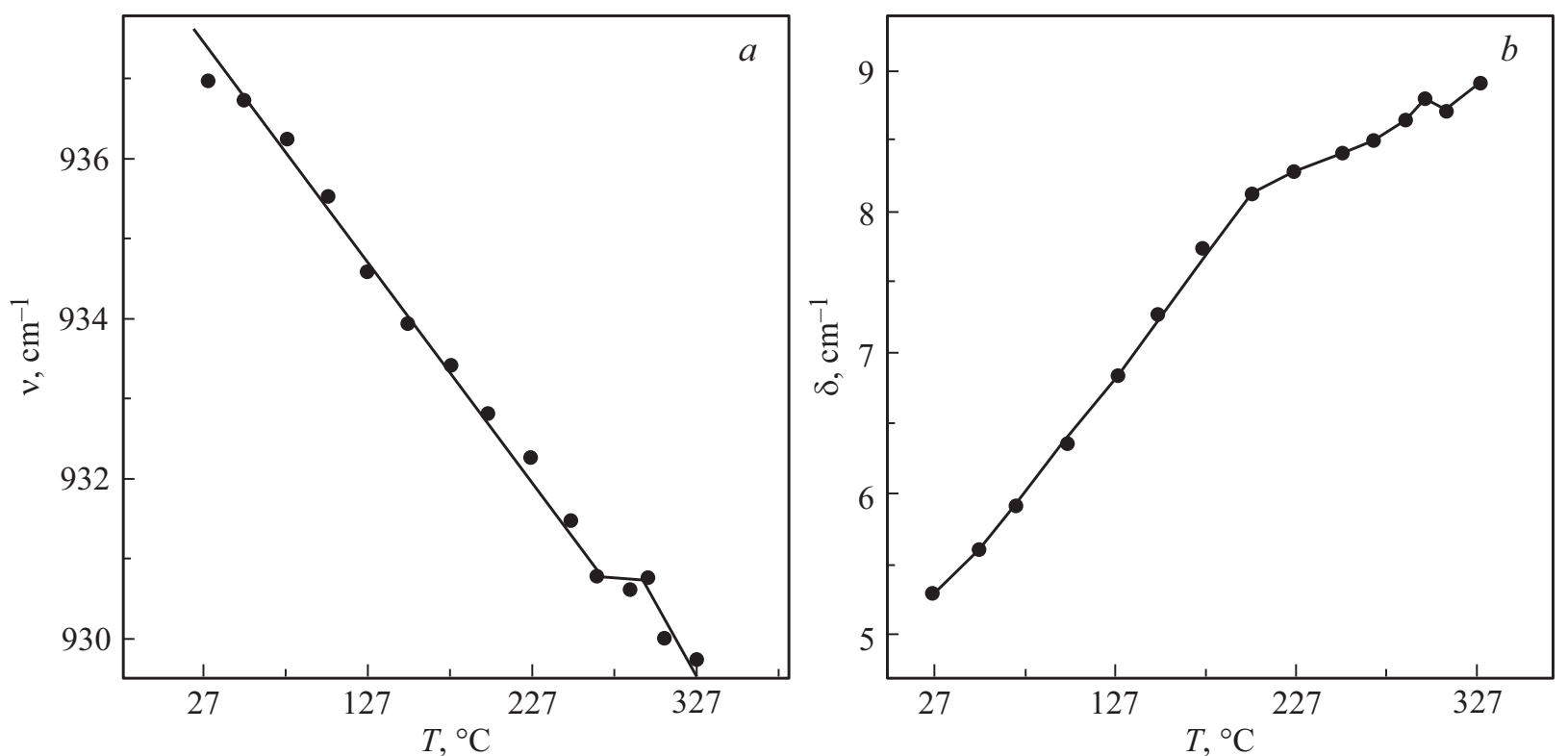

Рис. 1. Температурная зависимость частоты $v(T)$ и ширины $\delta(T)$ спектрального контура $v_{1}(A)$ аниона $\mathrm{ClO}_{4}^{-}$в кристаллическом перхлорате калия.
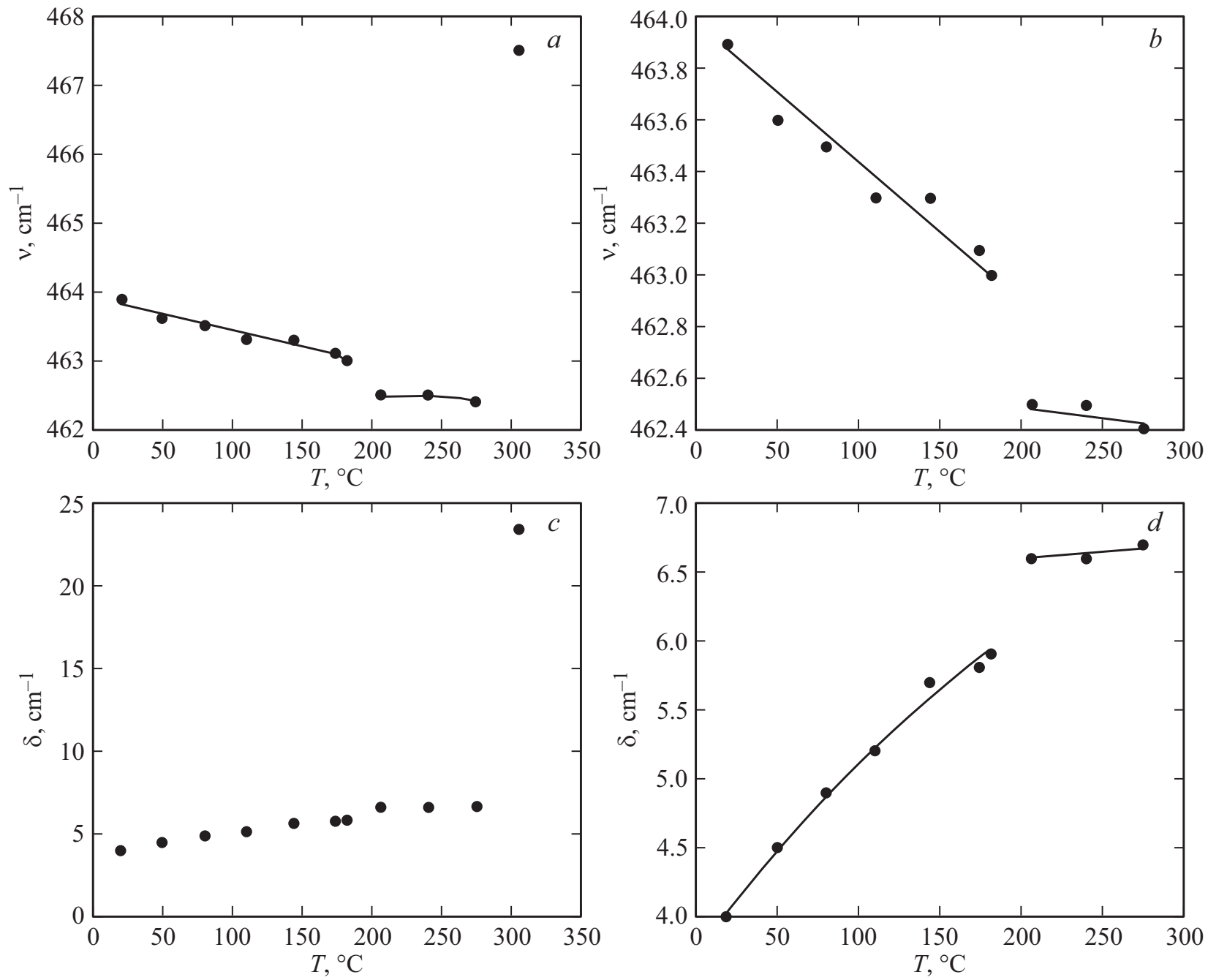

Рис. 2. Температурная зависимость частоты $v(T)(a, b)$ и ширины $\delta(T)(c, d)$ спектрального контура $\nu_{2}(E)$ аниона $\mathrm{ClO}_{4}^{-}$в кристаллическом перхлорате калия. 
При исследовании дважды вырожденного колебания $v_{2}(E)$ (рис. 2, $\left.a, b\right)$ мы не наблюдали снятия вырождения, что может быть связано с тем, что внутрикристаллические поля, в которых находятся подобные группы $\left(\mathrm{ClO}_{4}^{-}\right.$и искаженные октаэдры $\left.\mathrm{MClO}_{4}\right)$ элементарной ячейки, отличаются на малые величины, и ряд полос, обусловленных внутренними и внешними колебаниями кристаллической решетки, перекрываются [33]. Также как и для колебания $v_{1}(A)$, в интервале температур $20-200^{\circ} \mathrm{C}$ с увеличением температуры происходит линейное убывание частоты и экспоненциальный рост ширины (рис. 2, $c, d$ ), но менее быстрый. При температуре $T \approx 200^{\circ} \mathrm{C}$ наблюдается скачок ширины и частоты. От температуры $200^{\circ} \mathrm{C}$ до точки фазового перехода практически не происходит изменения ширины и частоты. При фазовом переходе резко возрастает частота колебания и ширина контура $v_{2}(E)$.

При исследовании трижды вырожденного колебания $v_{4}\left(F_{2}\right)$ (рис. 3) мы можем наблюдать некоторые особенности изменения спектральных параметров с температурой. В низкотемпературной кристаллической фазе проявляются все три линии колебания $v_{4}\left(F_{2}\right)$, активные в КР, локализованных в частотном интервале $627-640 \mathrm{~cm}^{-1}$. Анализ температурных зависимостей частот показывает, что частота основной линии колебания $v_{4}\left(F_{2}\right)\left(627 \mathrm{~cm}^{-1}\right)$ с ростом температуры линейно возрастает, в области фазового перехода происходит излом и после фазового перехода частота линейно уменьшается. Частоты остальных линий колебания $v_{4}\left(F_{2}\right)$ с ростом температуры линейно убывают и после температуры $200^{\circ} \mathrm{C}$ оба пика исчезают. На температурной зависимости ширины спектрального контура можно выделить три участка (рис. $3, b, c)$. На первом интервале от 20 до $200^{\circ} \mathrm{C}$ ширина экспоненциально растет, в точке $200^{\circ} \mathrm{C}$ происходит перегиб, при фазовом переходе происходит резкое возрастание ширины.

Сравнительный анализ спектральных параметров колебаний $v_{1}(A), v_{2}(E)$ и $v_{4}\left(F_{2}\right)$ позволяет сделать следующие выводы. Экспоненциальный рост ширины свидетельствует о том, что здесь проявляются процессы ориентационной релаксации, носящие активационный характер. Малое изменение ширины с ростом температуры в предпереходной области у всех трех колебаний можно связать с насыщением вращательной подвижности аниона [46], что свидетельствует об изменении локального окружения и межионных взаимодействий задолго до температуры структурного фазового перехода первого рода.

Дальнейшее увеличение температуры приводит к неустойчивости низкотемпературной кристаллической фазы и переходу к новой высокотемпературной кристаллической фазе. В области фазового перехода наблюдается излом температурных зависимостей частоты и ширины. Резкий скачок ширины и частоты колебаний $v_{2}(E)$ и $v_{4}\left(F_{2}\right)$ при фазовом переходе связан с изменением симметрии кристалла в результате структурного превращения.
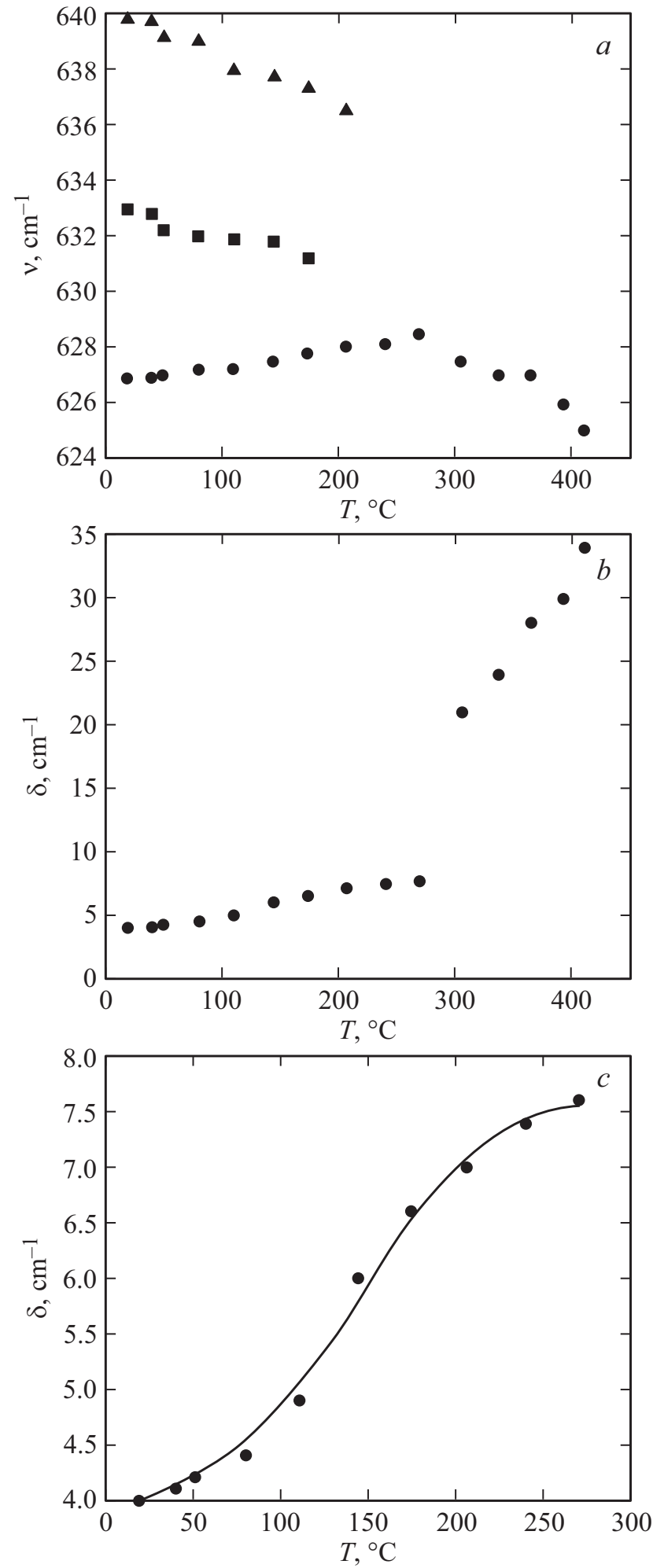

Рис. 3. Температурная зависимость частоты $v(T)(a)$ и ширины $\delta(T)(b, c)$ спектрального контура $v_{4}\left(F_{2}\right)$ аниона $\mathrm{ClO}_{4}^{-}$ в кристаллическом перхлорате калия.

Путем обработки экспериментальных данных по температурному уширению спектральной линии $v_{1}(A)$ методом наименьших квадратов по формуле (5) получе- 
ны следующие результаты: $U=11 \mathrm{~kJ} / \mathrm{mol}, v_{L}=97 \mathrm{~cm}^{-1}$, $\delta_{0}=4.6 \mathrm{~cm}^{-1}$.

Для низкотемпературной фазы по данным для колебания $v_{1}(A)$ проведены расчеты по методике, описанной в [47]. Оценены следующие параметры: $J-$ эффективный момент инерции; $\tau_{\text {вс }}-$ время между столкновениями; $\varepsilon-$ угловой шаг диффузии (табл. 1).

Анализ экспериментальных данных и времен переориентации дает основание полагать, что в $\mathrm{KClO}_{4}$ переориентация происходит по френкелевскому типу, т.е. представляет собой активационный процесс. Сравнительно малое изменение ширин у всех трех мод, начиная с температуры $200^{\circ} \mathrm{C}$, и появление перегиба на температурной зависимости ширины моды $v_{4}\left(F_{2}\right)$ свидетельствует об обнаружении здесь предпереходной области.

Были вычислены также интегральная интенсивность

$$
M_{0}=\int I(\omega) d \omega
$$

и спектральные моменты порядка $n(n=1,2,3,4)$

$$
M_{n}=\int I(\omega)\left(\omega-\omega_{0}\right)^{n} d \omega .
$$

Эти данные представлены в табл. 2.

Для описания динамики молекулярных анионов в исследованном веществе использовался аппарат временных корреляционных функций (ВКФ) $G(t)$, который позволяет количественно охарактеризовать во времени

Таблица 1. Параметры переориентации аниона $\mathrm{ClO}_{4}^{-}$в кристаллическом $\mathrm{KClO}_{4}$

\begin{tabular}{r|c|c|c|c}
\hline$T,{ }^{\circ} \mathrm{C}$ & $\tau_{R}, 10^{-12} \mathrm{~s}$ & $J / J_{0}$ & $\tau_{\mathrm{Bc}}, 10^{-12} \mathrm{~s}$ & $\varepsilon$, degrees \\
\hline 25 & 15.15 & 18.2 & 0.30 & 5.7 \\
50 & 10.73 & 13.4 & 0.29 & 6.7 \\
75 & 7.99 & 10.4 & 0.28 & 7.6 \\
99 & 6.24 & 8.4 & 0.27 & 8.4 \\
127 & 4.86 & 6.8 & 0.26 & 9.4 \\
152 & 4.00 & 5.7 & 0.25 & 10.2 \\
177 & 3.36 & 5.0 & 0.25 & 11.0 \\
202 & 2.88 & 4.4 & 0.24 & 11.7
\end{tabular}

Пр и м е ч ан и е. $J_{0}=6.22 \cdot 10^{-45} \mathrm{~kg} \cdot \mathrm{m}^{2}-$ момент инерции изолированного аниона $\mathrm{ClO}_{4}^{-}$(симметрия $S_{4}$ ).

Таблица 2. Спектрально-релаксационные характеристики колебания $v_{1}(A)$ аниона $\mathrm{ClO}_{4}^{-}$в кристаллическом $\mathrm{KClO}_{4}$

\begin{tabular}{c|c|c|c|c|c|c|c|c}
\hline $\begin{array}{c}T, \\
{ }^{\circ} \mathrm{C}\end{array}$ & $\begin{array}{c}v, \\
\mathrm{~cm}^{-1}\end{array}$ & $\begin{array}{c}\delta, \\
\mathrm{cm}^{-1}\end{array}$ & $\begin{array}{c}M_{2}, \\
\mathrm{~cm}^{-2}\end{array}$ & $\begin{array}{c}\tau, \\
10^{-12} \mathrm{~s}\end{array}$ & $\begin{array}{c}\delta_{1}, \\
\mathrm{~cm}^{-1}\end{array}$ & $\begin{array}{c}\delta_{2}, \\
\mathrm{~cm}^{-1}\end{array}$ & $\begin{array}{c}\tau_{1}, \\
10^{-12} \mathrm{~s}\end{array}$ & $\begin{array}{c}\tau_{2}, \\
10^{-12} \mathrm{~s}\end{array}$ \\
\hline 50 & 936.8 & 5.6 & 76.58 & 2.2 & 0.094 & 6.26 & 113.55 & 2.5 \\
227 & 932.2 & 8.3 & 223.11 & 1.7 & 3.99 & 5.48 & 2.66 & 2.86 \\
291 & 930.4 & 8.6 & 244.22 & 1.6 & 3.2 & 6.5 & 3.33 & 2.41 \\
310 & 930.1 & 8.7 & 323.7 & 1.6 & 1.03 & 6.85 & 5.22 & 2.29
\end{tabular}

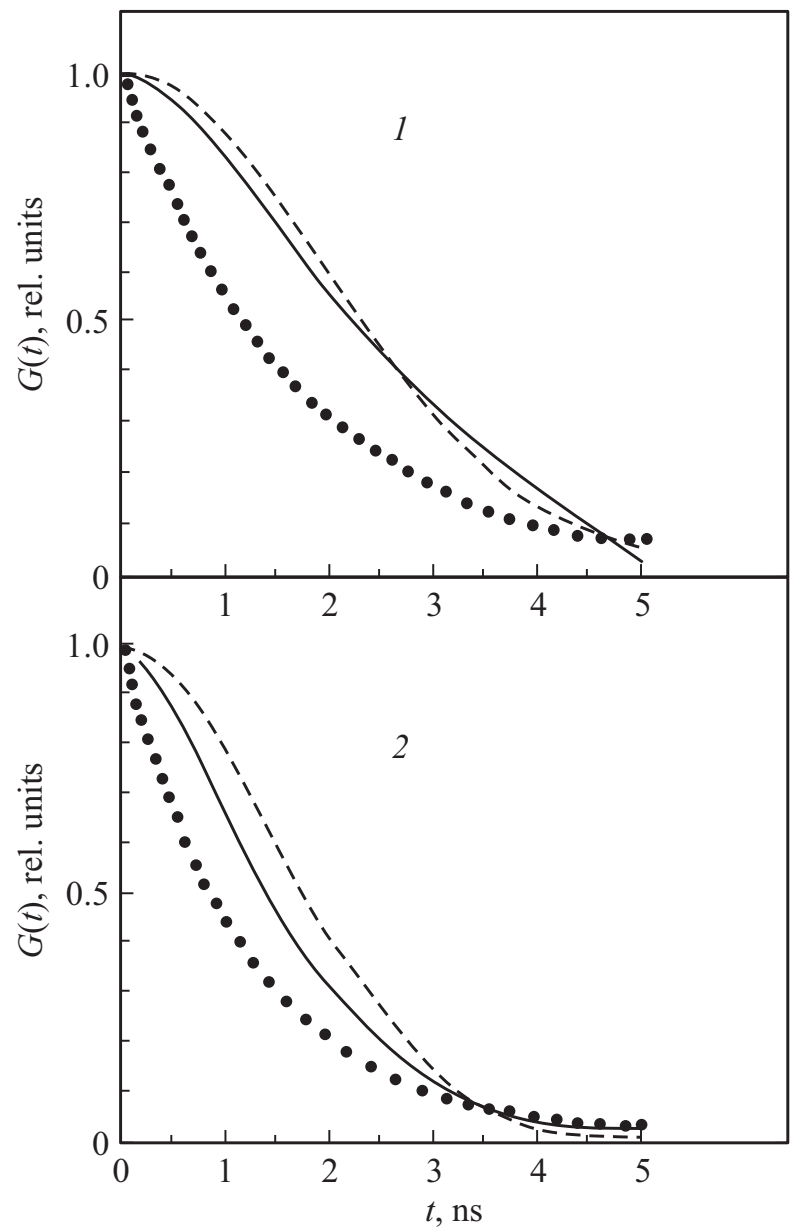

Рис. 4. Временные корреляционные функции колебательной релаксации аниона $\mathrm{ClO}_{4}^{-}$в кристаллическом перхлорате калия при 99 (1) и $227^{\circ} \mathrm{C}$ (2). Сплошная линия соответствует $G(t)$, вычисленной по данным эксперимента, пунктир и точки - гауссова $G_{2}(t)$ и экспоненциальная $G_{1}(t)$ кривые соответственно.

процесс релаксации колебательных состояний частиц, обусловленный взаимодействиями и движением [48]. ВКФ вычислены по экспериментальным спектрам с помощью преобразования Фурье по всему спектральному интервалу

$$
G(t)=\int I(\omega) \cos (\omega t) d \omega .
$$

ВКФ, полученные при различных температурах, представлены на рис. 4. Используя $G(t)$, вычислены времена колебательной релаксации

$$
\tau=\int_{0}^{\infty} G(t) d t .
$$

В нашем случае колебательный контур $I(\omega)$, наблюдаемый в эксперименте, представляет собой свертку дисперсионного (лоренцева) $I_{1}(\omega)$ и гауссова $I_{2}(\omega)$ 
контуров. Поэтому

$$
G(t)=G_{1}(t) \cdot G_{2}(t)
$$

где $G_{1}(t), G_{2}(t)$ - экспоненциальная (лоренцева) и гауссова ВКФ соответственно

$$
\begin{gathered}
G_{1}(t)=\exp (-b t), \quad G_{2}(t)=\exp \left(-a t^{2}\right), \\
G(t)=\exp \left(-a t^{2}-b t\right), \quad \ln [G(t)]=a t^{2}+b t, \\
\delta_{1}=b /(\pi c), \quad \tau_{1}=1 / b, \quad \delta_{2}=\frac{1}{\pi \cdot c} \cdot[\ln (2) \cdot a]^{1 / 2}, \\
\tau_{2}=[\pi /(4 a)]^{1 / 2} .
\end{gathered}
$$

Методом наименьших квадратов были вычислены значения постоянных $a$ и $b$, а с их помощью определены параметры $\delta_{1}, \tau_{1}, \delta_{2}, \tau_{2}$ (табл. 2).

Анализ ВКФ и времен релаксации показывает, что с ростом температуры вклад однородного уширения $\delta_{1}$ в общую ширину спектральной полосы возрастает. Это можно объяснить тем, что при нагревании интенсифицируются процессы колебательной дефазировки (возрастает частота столкновений ионов). В то же время вклад неоднородного уширения $\delta_{2}$ изменяется мало. Нагревание кристалла приводит, с одной стороны, к разрушению неоднородностей, а с другой - к ускорению диффузионных переходов анионов в новые локальные окружения. Конкуренция этих двух процессов приводит к слабым изменениям величины $\delta_{2}$. Из рис. 4 видно, что если при низких температурах $G(t)$ имеет почти гауссову форму, то с увеличением температуры $G(t)$ приближается к экспоненциальному виду. При этом уменьшается относительный вклад процессов неоднородного уширения и растет относительный вклад процессов однородного уширения. Это можно объяснить преобладанием механизмов, связанных с взаимодействием и динамикой частиц над механизмами, связанными с неоднородностью системы.

Сравнительный анализ спектральных параметров колебаний $v_{1}(A), v_{2}(E)$ и $v_{4}\left(F_{2}\right)$ для кристаллического перхлората калия позволяет сделать вывод о том, что изменение локального окружения перхлорат-иона происходит при $180-200^{\circ} \mathrm{C}$, то есть задолго до фазового перехода, и в интервале температур $180-300^{\circ} \mathrm{C}$ наблюдается предпереходная область.

\section{5. Результаты по перхлорату цезия}

Спектры КР кристаллического перхлората цезия снимали в области полносимметричного колебания $v_{1}(A)$, а также в области дважды вырожденного колебания $\nu_{2}(E)$ и трижды вырожденного колебания $v_{4}\left(F_{2}\right)$. Температурные зависимости максимальной интенсивности, частоты и ширины спектральных контуров, соответствующих колебаниям $v_{1}(A)$ (рис. 5), $v_{2}(E)$ (рис. 6) и $v_{4}\left(F_{2}\right)$ (рис. 7) аниона $\mathrm{ClO}_{4}^{-}$, исследовались в интервале $25-351^{\circ} \mathrm{C}$.
На температурных зависимостях интенсивности, частоты и ширины (рис. 5) спектрального контура колебания $v_{1}(A)$ наблюдаются три участка. Первый участок охватывает область температур $25-135^{\circ} \mathrm{C}$, второй уча-
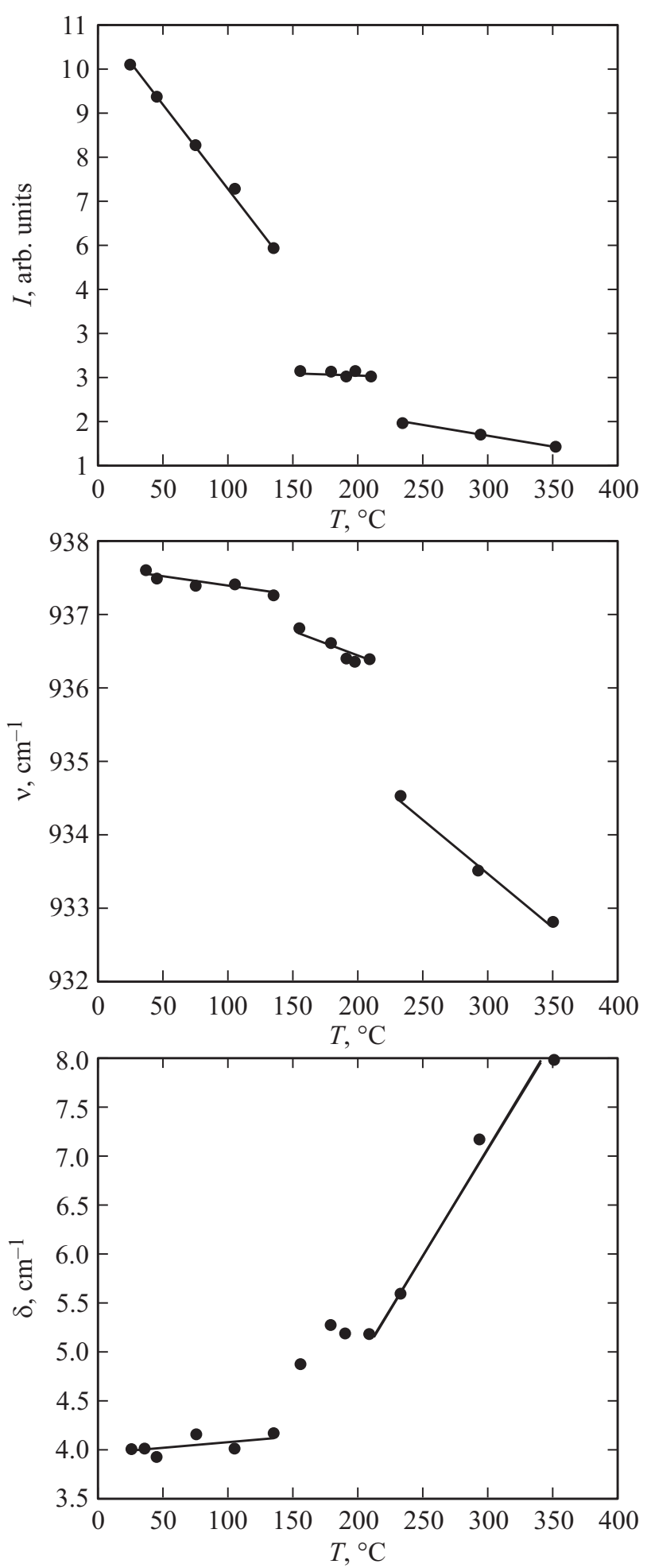

Рис. 5. Температурные зависимости максимальной интенсивности $I(T)$, положения максимума $v(T)$ и ширины $\delta(T)$ линии спектра КР, соответствующего колебанию $v_{1}(A)$ аниона $\mathrm{ClO}_{4}^{-}$ кристаллического перхлората цезия. 

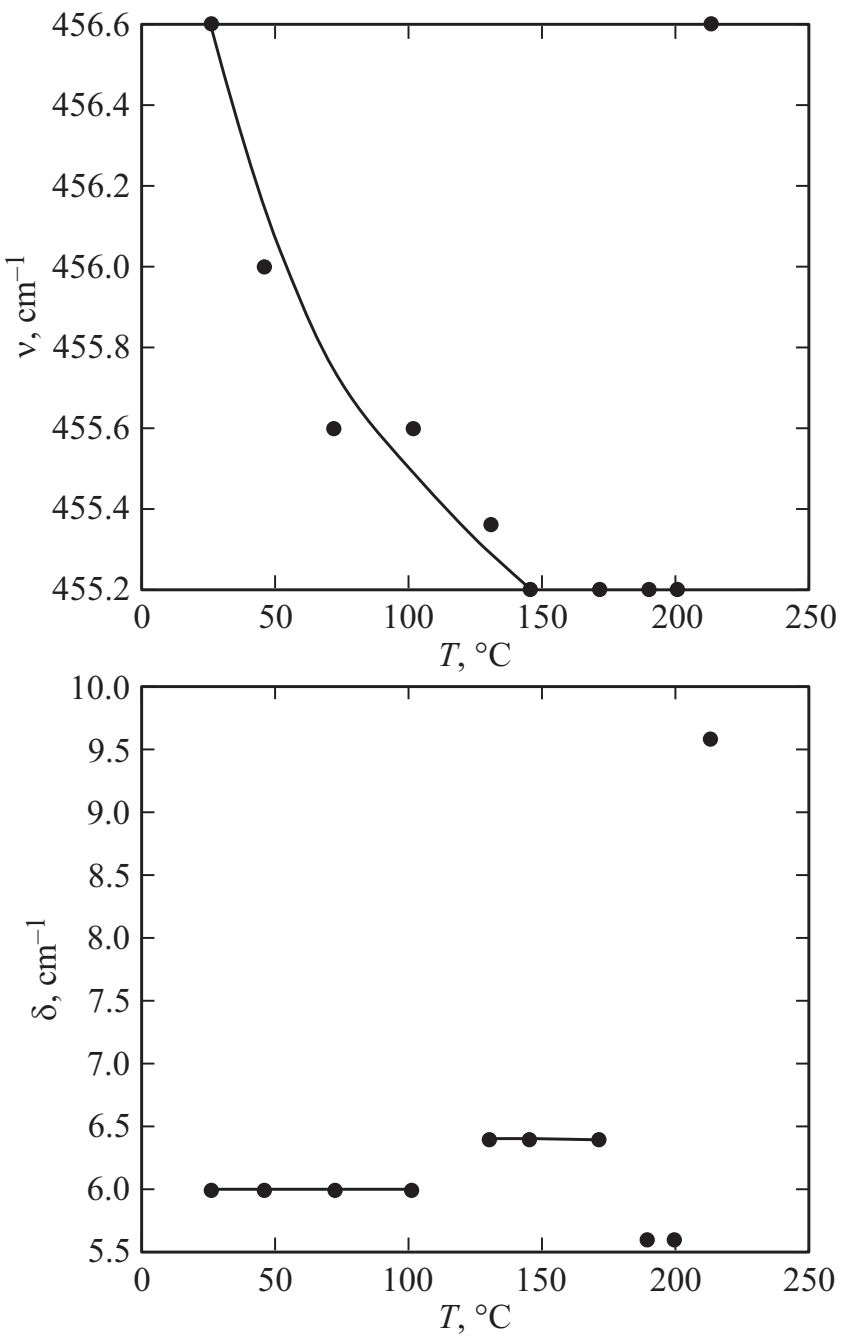

Рис. 6. Температурная зависимость частоты $v(T)$ и ширины $\delta(T)$ спектрального контура $v_{2}(E)$ аниона $\mathrm{ClO}_{4}^{-}$в кристаллическом перхлорате цезия.

сток $152-209^{\circ} \mathrm{C}$, третий участок $233-351^{\circ} \mathrm{C}$. В области температур $135-152^{\circ} \mathrm{C}$, а также в области фазового перехода при температуре $209^{\circ} \mathrm{C}$ наблюдаются изломы (скачки) температурных зависимостей интенсивности, частоты и ширины. Объяснить такую корреляцию в поведении температурных зависимостей спектральных характеристик можно, предположив наличие предпереходной области в кристаллическом перхлорате цезия на участке температур $152-209^{\circ} \mathrm{C}$.

При исследовании дважды вырожденного колебания $v_{2}(E)$ мы наблюдали слабое снятие вырождения, близкое по характеру к тому, что обнаружено авторами в работе [37]. Две компоненты дважды вырожденного колебания $\nu_{2}(E)$ не разрешаются в виде двух отдельных пиков, а сливаются в одну широкую полосу. С ростом температуры каждая из компонент уширяется, расстояние между компонентами уменьшается. Конкуренция этих двух взаимно противоположных процессов приводит к тому, что ширина результирующей полосы мало меняется в области температур $26-101^{\circ} \mathrm{C}$ (рис. 6). В области температур $101-130^{\circ} \mathrm{C}$ наблюдается излом (скачок) температурной зависимости ширины. Также как и для колебания $v_{1}(A)$, с увеличением температуры в интервале $26-130^{\circ} \mathrm{C}$ происходит сдвиг положения максимума спектрального контура в сторону меньших волновых чисел. В области температур $130-145^{\circ} \mathrm{C}$ наблюдается излом температурной зависимости частоты. Появление изломов в области температур $101-145^{\circ} \mathrm{C}$ на температурных зависимостях частоты и ширины свидетельствует о том, что предпереходные явления влияют на поведение спектральных характеристик моды $v_{2}(E)$. После фазового перехода происходит резкое возрастание частоты колебания и ширины соответствующего спектрального контура.

При исследовании трижды вырожденного колебания $v_{4}\left(F_{2}\right)$ мы наблюдали только две линии колебания $v_{4}\left(F_{2}\right)$ активных в КР, локализованных в частотном интервале $628-632 \mathrm{~cm}^{-1}$ (рис. 7). Анализ температурных зависимостей положений максимумов линий дублета показывает,
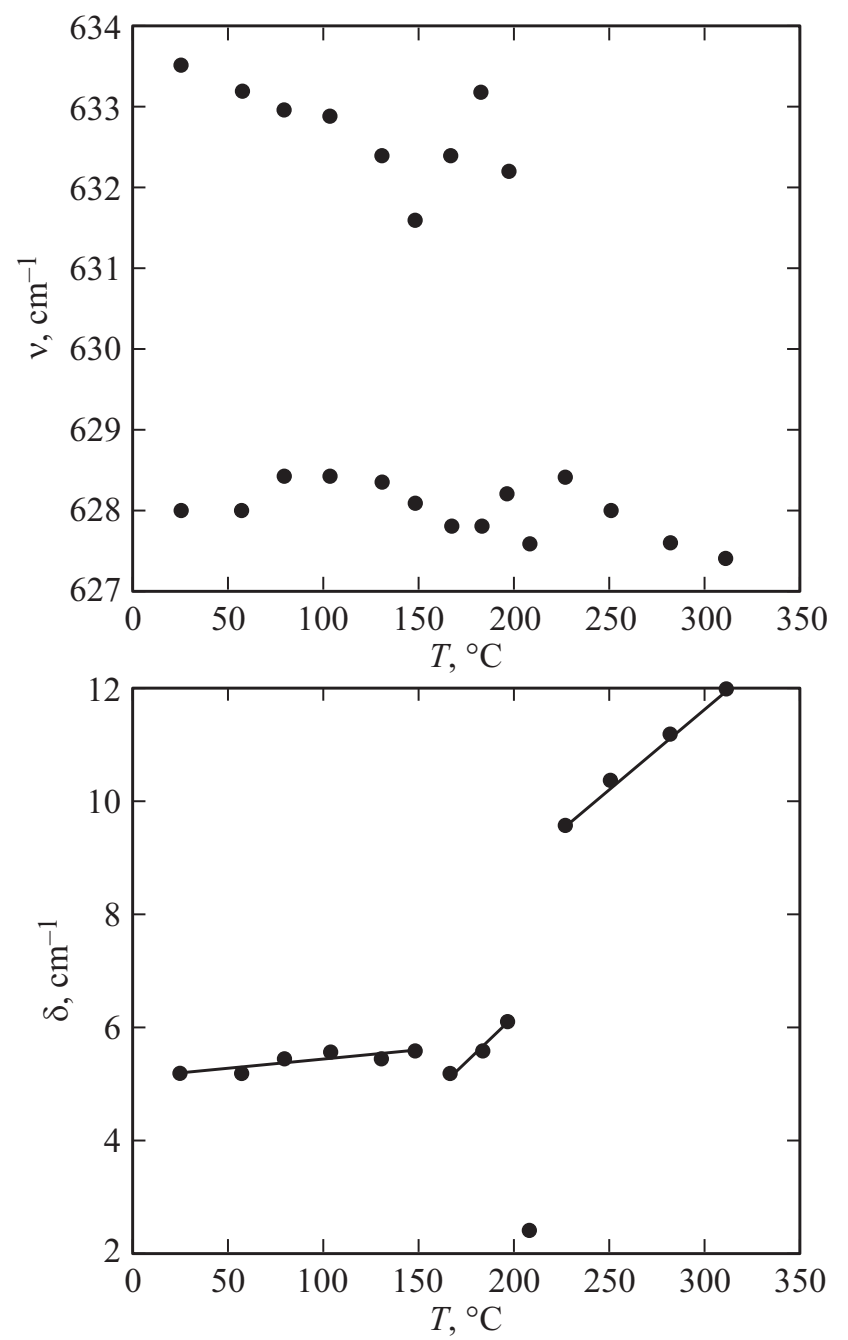

Рис. 7. Температурная зависимость частоты $v(T)$ и ширины $\delta(T)$ спектрального контура $v_{4}\left(F_{2}\right)$ аниона $\mathrm{ClO}_{4}^{-}$в кристаллическом перхлорате цезия. 
что поведение их носит сложный характер. Это может быть связано с тем, что с ростом температуры происходит сближение пиков дублета, и в области температуры $197^{\circ} \mathrm{C}$ второй пик исчезает. На температурной зависимости частоты в области фазового перехода происходит скачок, и, начиная с температуры $227^{\circ} \mathrm{C}$, до температуры $311^{\circ} \mathrm{C}$ имеет место линейное убывание частоты. На температурной зависимости ширины спектрального контура тоже можно выделить три участка. На первом интервале от 26 до $148^{\circ} \mathrm{C}$ ширина слабо растет, в точке $148^{\circ} \mathrm{C}$ происходит излом, в интервале $167-197^{\circ} \mathrm{C}$ ширина растет с температурой быстрее, и от температуры $227^{\circ} \mathrm{C}$ до $311^{\circ} \mathrm{C}$ происходит резкое возрастание ширины. Фазовый переход при температуре $209^{\circ} \mathrm{C}$ характеризуется значительными скачками ширины.

Сравнительный анализ спектральных параметров колебаний $v_{1}(A), v_{2}(E)$ и $v_{4}\left(F_{2}\right)$ для кристаллического перхлората цезия позволяет сделать вывод о том, что изменение локального окружения перхлорат-иона происходит при $130-160^{\circ} \mathrm{C}$, то есть задолго до фазового перехода, и в интервале температур $130-208^{\circ} \mathrm{C}$ наблюдается предпереходная область.

\section{6. Обсуждение результатов}

Наблюдаемые нами особенности на температурных зависимостях параметров линий КР кристаллов $\mathrm{KClO}_{4}$ и $\mathrm{CsClO}_{4}$ за $70 \div 120 \mathrm{~K}$ до температур фазового перехода находятся в полном соответствии с результатами работ [20-23], в которых наблюдалось аномальное поведение двупреломления в кристаллах $\mathrm{KPb}_{2} \mathrm{Br}_{5}$, $\left(\mathrm{NH}_{4}\right)_{2} \mathrm{WO}_{2} \mathrm{~F}_{4}, \mathrm{KPb}_{2} \mathrm{Cl}_{5},(\mathrm{NH} 4)_{2} \mathrm{NbOF}_{5}$ за $30 \div 130 \mathrm{~K}$ до температуры фазового перехода. Таким образом, можно предположить, что наличие предпереходных состояний является общим свойством структурных фазовых переходов первого рода в кристаллах.

Сравнительный анализ спектроскопических параметров колебания $v_{1}(A)$ для $\mathrm{KClO}_{4}$ (рис. 1) и $\mathrm{CsClO}_{4}$ (рис. 5) позволяет сделать вывод о зависимости частоты полносимметричного колебания от ионного радиуса катиона. С увеличением ионного радиуса частота уменьшается. Частоту колебания $v_{1}(A)$ определяет размер катиона (ионный радиус), задающий объем „катионной полости“ кристаллической решетки. Чем больше ионный радиус катиона, тем больше эта полость и тем дальше друг от друга отстоят ионы $\mathrm{ClO}_{4}^{-}$и, следовательно, тем менее напряженной является сама кристаллическая решетка. Это приводит к увеличению симметрии перхлорат-иона.

Результаты экспериментальных измерений показывают, что температура и фазовые переходы существенно влияют на спектры перхлоратов щелочных металлов. При этом изменению подвергаются практически все параметры полос: положение максимума (частота), форма и ширина контура, интенсивность. Такие изменения параметров колебательных полос при температурнофазовых превращениях являются следствием возмущения характеристик молекулы за счет межчастичных взаимодействий. Под их влиянием претерпевают изменения равновесные длины связей, углы между связями и колебательные постоянные молекулы.

Температурно-фазовые зависимости положений максимумов изученных нами полос спектров КР кристаллических перхлоратов калия и цезия представлены на рис. $1-3,5-7$. Общим для всех исследованных соединений в области колебания $v_{1}(A)$ является то, что температурные зависимости частот носят линейный характер и, как правило, частота уменьшается с ростом температуры. В точках фазовых переходов частоты колебаний изменяются скачками.

Температурные зависимости ширин (рис. 1-3, 5-7) носят приближенно экспоненциальный характер. Причины температурного уширения колебательных линий в спектрах кристаллов могут быть разными. В рамках поворотно-релаксационного механизма уширения [49] наблюдаемые в эксперименте температурные зависимости ширин линий в спектрах КР перхлоратов можно связать с реориентационным движением анионов $\mathrm{ClO}_{4}^{-}$ в кристаллических решетках. Вместе с тем соответствующие вклады в ширины линий могут вносить также процессы, обусловленные распадом данного колебания на другие внутримолекулярные колебания с участием фононов решетки [50-52]. Этот релаксационный механизм реализуется в случае, если молекулярный ион имеет близкие по частотам внутримолекулярные колебания $v_{i}$ и $v_{j}$. При этом релаксация колебания $v_{i}$ молекулярного иона может сопровождаться возбуждением колебания $v_{j}$, а разность энергий передаваться фононам решетки. Такой релаксационный механизм реализуется при выполнении следующих условий:

$$
v_{j}<v_{i}, \quad v_{i}-v_{j}<v_{m},
$$

где $v_{m}$ - максимальная частота фононного спектра кристалла. Для $\mathrm{KClO}_{4}$ и $\mathrm{CsClO}_{4}$ в среднем эта разность равна $v_{1}-v_{4}=330 \mathrm{~cm}^{-1}$ и $v_{4}-v_{2}=170 \mathrm{~cm}^{-1}$.

В нашем случае вклад этого механизма в ширину полосы мал, так как в перхлорате калия $v_{m}=184 \mathrm{~cm}^{-1}$, а в перхлорате цезия $v_{m}=188 \mathrm{~cm}^{-1}$ [33]. Таким образом, условие (14) не выполняется для полносимметричного колебания $v_{1}$ перхлорат-иона, а для колебания $v_{4}$ разница $170 \mathrm{~cm}^{-1}$ близка к максимальной частоте фононного спектра кристалла.

Вклады, связанные как с переориентацией молекулярного иона, так и фононным распадом, зависят от температуры. Поэтому выбор того или иного механизма уширения для объяснения результатов эксперимента требует детального анализа характера температурных зависимостей ширин и формы соответствующих контуров в спектрах кристаллов. В рассматриваемом случае в пользу поворотно-релаксационного механизма уширения свидетельствует несколько обстоятельств. Во-первых, температурные зависимости ширин полос КР перхлоратов 
носят экспоненциальный характер. Во-вторых, в соответствии с теорией [53], рассматривающей влияние переориентации на ширины линий в спектрах кристаллов, форма контуров полос КР перхлоратов в предпереходной области близка к лоренцевой. Наконец, очевидно и то, что для квазисферического аниона $\mathrm{ClO}_{4}^{-}$стерические препятствия его поворотному движению в кристаллах будут незначительными и потому его реориентационная подвижность должна заметно усилиться с повышением температуры кристаллов. Это говорит в пользу того, что процесс ориентационного разупорядоченния анионов в кристаллах перхлоратов носит активационный характер.

Однако при сравнении спектральных линий $\mathrm{KClO}_{4}$ и $\mathrm{CsClO}_{4}$ можно заметить, что чем более искажен перхлорат-ион в кристаллической решетке, тем сильнее проявляется температурная зависимость реориентационных процессов. Благодаря искажению перхлорат-иона в кристаллическом поле, переориентации аниона оказывают влияние на ширину спектра КР в области колебания $v_{1}$. Спектральные характеристики в частотных интервалах, отвечающих колебаниям $v_{2}$ и $v_{4}$ аниона, в большей степени подвержены влиянию ориентационной подвижности перхлорат-иона.

Сравнивая температурно-фазовые зависимости частот и ширин линий в спектрах $\mathrm{KP} \mathrm{KClO}_{4}$ и $\mathrm{CsClO}_{4}$ в области колебаний $v_{2}$ и $v_{4}$, мы также можем отметить как общие, так и отличающие их черты. Общим для обоих кристаллов является появление ярко выраженной предпереходной области (рис. 1-3, 5-7), свидетельствующей об изменении локального окружения аниона задолго до фазового перехода. Отличие в поведении спектральных характеристик связано также с большим искажением перхлорат-иона в кристалле $\mathrm{KClO}_{4}$. Это проявляется в том, что температурная зависимость ширины в перхлорате калия более близка к экспоненциальному виду (1-3), а также в том, что при снятии вырождения с колебания $v_{4}$ в $\mathrm{KClO}_{4}$ в спектре КР проявляются все три линии (рис. 3), в то время как в $\mathrm{CsClO}_{4}$ наблюдаются только две линии (рис. 7).

Таким образом, результаты проведенных нами экспериментов доказывают существование предпереходной области в исследованных нами перхлоратах $\mathrm{KClO}_{4}$ и $\mathrm{CsClO}_{4}$. В этой области происходит изменение локального окружения перхлорат-ионов и, как следствие этого, меняются структурно-динамические свойства солей задолго до структурного фазового перехода первого рода.

\section{7. Заключение}

Методами спектроскопии комбинационного рассеяния (КР) исследованы процессы молекулярной релаксации в перхлоратах калия $\left(\mathrm{KClO}_{4}\right)$ и цезия $\left(\mathrm{CsClO}_{4}\right)$. Показано, что в исследованных перхлоратах $\mathrm{KClO}_{4}$ и $\mathrm{CsClO}_{4}$ основным механизмом уширения колебательных полос является поворотно-релаксационный. Наблюдаемые в эксперименте температурные зависимости ширин линий в спектрах КР связываются с реориентационным движением перхлорат-ионов в кристаллической решетке. Установлено, что переориентация анионов $\mathrm{ClO}_{4}^{-}$в кристаллах перхлоратов $\mathrm{KClO}_{4}$ и $\mathrm{CsClO}_{4}$ происходит по активационному механизму. Рассчитаны временные и энергетические параметры переориентации анионов. Обнаружено, что в кристаллических перхлоратах $\mathrm{KClO}_{4}$ и $\mathrm{CsClO}_{4}$ структурный фазовый переход первого рода носит растянутый характер. Показано существование предпереходной области в исследованных перхлоратах $\mathrm{KClO}_{4}$ и $\mathrm{CsClO}_{4}$. Обнаружено, что в предпереходной области ширины колебательных полос мало изменяются, резко возрастая в точке фазового перехода. Установлено, что изменения структурно-динамических свойств и характера локального окружения анионов $\mathrm{ClO}_{4}^{-}$в предпереходной области перхлоратов $\mathrm{KClO}_{4}$ и $\mathrm{CsClO}_{4}$ зависят от вида катиона.

\section{Список литературы}

[1] М.Б. Смирнов, J. Heinka. ФТТ 42, 12, 2219 (2000).

[2] В.И. Зиненко, Н.Г. Замкова. ФТТ 43, 12, 2193 (2001).

[3] Jianjun Liu, Chun-gang Duan, W.N. Mei, R.W. Smith, J.R. Hardy. J. Solid State Chem. 163, 1, 294 (2002).

[4] А.А. Прохоров, Г.Н. Нейло, А.Д. Прохоров, А.С. Карначев. ФTT 48, 2, 321 (2006).

[5] Ю.Н. Журавлев, Д.В. Корабельников. ФТТ 51, 1, 65 (2009).

[6] M. Pravica, Y. Wang, D. Sneed, Sh. Reiser, M. White. Chem. Physics Lett. 660, 37 (2016).

[7] Д.В. Корабельников, Ю.Н. Журавлев. ФТТ 58, 6, 1129 (2016).

[8] Д.В. Корабельников, Ю.Н. Журавлев. ФТТ 59, 2, 248 (2017).

[9] А.Р. Алиев, И.Р. Ахмедов, М.Г. Какагасанов, З.А. Алиев, М.М. Гафуров, К.Ш. Рабаданов, А.М. Амиров. ФТТ 59, 4, 736 (2017).

[10] А. Уббелоде. Плавление и кристаллическая структура. Мир, М. (1969). С. 279.

[11] Г.Д. Копосов, Д.Ю. Бардюг. Письма в ЖТФ 33, 14, 80 (2007).

[12] Е.И. Демихов, В.К. Долганов, В.М. Филев. Письма в ЖЭТФ 37, 7, 305 (1983).

[13] М.А. Анисимов, Е.Е. Городецкий, В.Э. Поднек. Письма в ЖЭТФ 37, 8, 352 (1983).

[14] Е.И. Демихов, В.К. Долганов. Письма в ЖЭТФ 38, 8, 368 (1983).

[15] В.А. Кизель, С.И. Панин. Письма в ЖЭТФ 44, 2, 74 (1986).

[16] В.Г. Пушин, В.В. Кондратьев, В.Н. Хачин. Предпереходные явления и мартенситные превращения. УрО РАН, Екатеринбург (1998) 367 с.

[17] А.А. Клопотов, Т.Л. Чекалкин, В.Э. Гюнтер. ЖТФ 71, 6, 130 (2001).

[18] Е.И. Кузнецова. Дисс. канд. физ.-мат. наук. Институт физики металлов УрО РАН, Екатеринбург (2003). 115 с.

[19] В.Н. Гришков, А.И. Лотков, С.Ф. Дубинин, С.Г. Теплоухов, В.Д. Пархоменко. ФТТ 46, 8, 1348 (2004).

[20] С.В. Мельникова, Л.И. Исаенко, В.М. Пашков, И.В. Певнев. ФТТ 47, 2, 319 (2005).

[21] С.В. Мельникова, В.Д. Фокина, Н.М. Лапташ. ФТТ 48, 1 , $110(2006)$ 
[22] С.В. Мельникова, Л.И. Исаенко, В.М. Пашков, И.В. Певнев. ФТТ 48, 11, 2032 (2006).

[23] С.В. Мельникова, Н.М. Лапташ, К.С. Александров. ФТТ 52, 10, $2023(2010)$.

[24] Е.Е. Слядников. ФТТ 46, 6, 1065 (2004).

[25] Е.Е. Слядников. Письма в ЖТФ 31, 5, 30 (2005).

[26] Е.Е. Слядников. ФТТ 47, 3, 469 (2005).

[27] Е.Е. Слядников. Дисс. докт. физ.-мат. наук. Институт физики прочности и материаловедения СО РАН, Томск (2005). $259 \mathrm{c}$.

[28] А.Н. Втюрин, А. Белю, А.С. Крылов, М.Л. Афанасьев, А.П. Шебанин. ФТТ 43, 12, 2209 (2001).

[29] Рассеяние света вблизи точек фазовых переходов/ Под ред. Г.З. Камминза, А.П. Леванюка. Наука, М. (1990) 414 с.

[30] С.В. Карпов, А.А. Шултин. ФТТ 17, 10, 2868 (1975).

[31] Я.Я. Аболиньш, С.В. Карпов, А.А. Шултин. ФТТ 20, 12, 3660 (1978).

[32] M.M. Gafurov, A.R. Aliev, I.R. Akhmedov. Spectrochimica Acta 58A, 12, 2683 (2002).

[33] Е.К. Галанов, И.А. Бродский. ФТТ 10, 11, 3392 (1968).

[34] С.П. Чернышева, В.И. Снежков, В.А. Сединкин. Укр. хим. журнал 43, 8, 874 (1977).

[35] N. Toupry-Krauzman, H. Poulet. J. Raman Spectroscopy 7, 1, 1 (1978).

[36] N. Toupry, H. Poulet, M. Le Postollec, R.M. Pick, M. Yvinec. J. Raman Spectroscopy 14, 3, 166 (1983).

[37] H.D. Lutz, R.A. Becker, W. Eckers, B.G. Holscher, H.J. Berthold. Spectrochimica Acta 39A, 1,7 (1983).

[38] S. Seetharaman, H.L. Bhat, P.S. Narayanan. Indian J. Physics 58B, 294 (1984).

[39] Н.А. Чумаевский, Т.А. Иванова, В.П. Тарасов. Журнал неорган. химии 37, 9, 2064 (1992).

[40] Е.Ю. Тонков. Фазовые диаграммы соединений при высоком давлении. Наука, М. (1983). 280 с.

[41] Г.Я. Любарский. Теория групп и ее применение в физике. ГИФМЛ, М. (1958). 356 с.

[42] С. Багавантам, Т. Венкатарайуду. Теория групп и ее применение к физическим проблемам. ИЛ, М. (1959). $301 \mathrm{c}$.

[43] A.R. Aliev, M.M. Gafurov, I.R. Akhmedov. Mol. Phys. 100, 21, 3385 (2002).

[44] L.H. Jones. J. Chemical Phys. 28, 6, 1234 (1958).

[45] A.R. Aliev, M.M. Gafurov, I.R. Akhmedov. Chem. Phys. Lett. 359, 3-4, 262 (2002).

[46] А.Р. Алиев, А.И. Акаева, А.З. Гаджиев. Расплавы 4, 59 (2002).

[47] A.R. Aliev, M.M. Gafurov, I.R. Akhmedov. Chem. Phys. Lett. 353, 3-4, 270 (2002).

[48] A.R. Aliev, A.Z. Gadzhiev. J. Mol. Liquids 107, 1-3, 59 (2003).

[49] А.В. Раков. Тр. ФИАН СССР 27, 111 (1964).

[50] А.Р. Алиев, М.М. Гафуров. Журн. физ. химии 75, 3, 477 (2001).

[51] А.Р. Алиев, И.Р. Ахмедов, М.Г. Какагасанов, 3.А. Алиев, М.М. Гафуров, К.Ш. Рабаданов, А.М. Амиров. Оптика и спектроскопия 123, 4, 575 (2017).

[52] А.Р. Алиев, И.Р. Ахмедов, М.Г. Какагасанов, 3.А. Алиев, М.М. Гафуров, К.Ш. Рабаданов, А.М. Амиров. ФТТ 60, 2, 341 (2018).

[53] К.А. Валиев, К.А. Бильданов. Оптика и спектроскопия 23, 5,842 (1967). 